Jurnal Widya Sastra Pendidikan Agama Hindu, Vol. 3, No. 2, 2020 e-ISSN: 2656-7466, p-ISSN: 1907-9559

DOI: https://doi.org/10.36663/wspah.v3i2

\title{
KAJIAN AJARAN ETIKA DALAM KITAB SARASAMUCCAYA
}

\author{
I Wayan Gara \\ Nyoman Sri Weda Yani \\ STKIP Agama Hindu Singaraja \\ iwayan.gara@gmail.com
}

\begin{abstract}
ABSTRAK
Etika bagian dari ajaran tiga kerangka dasar Agama Hindu termuat dalam kitab Sarasamuccaya. Adapun kitab Sarasamuccaya merupakan pedoman tingkah laku yang baik dalam kehidupan manusia, yang di dalamnya terdapat ajaran religi dan etika. Masalah yang diangkat dalam penelitian ini mengenai aspek (ajaran) etika dalam kitab Sarasamuccaya, tujuan penelitian ini untuk mengkaji aspek etika dalam kitab Sarasamuccaya, sedangkan manfaatnya diharapkan dapat meningkatnya wawasan dan moral atau etika umat Hindu seperti yang tersirat dalam kitab Sarasamuccaya. Pembahasan terhadap masalah penelitian ini bertumpu pada tiga teori : teori religi, teori fungsional-struktural, dan teori simbol, teori etika, dan teori interpretasi/hermeneutika. Adapun metode penelitiannya terdiri atas: (1) metode pengumpulan data, (2) metode dokumentasi, (3) metode analisis data, hasil pengkajian dalam tulisan ini meliputi : (1) catur purusa artha, yang terdiri atas: dharma, artha, kama, dan moksa; (2) trikaya, yang terdiri atas: kayika parisudha, wacika parisudha, manacika parisudha; (3) hormat kepada orang lain dan orang tua, dan (4) ajaran dasa yama, yang terdiri atas: Anrsangsya, ksama, satya, ahingsa, dama, arjawa, priti, prasada, madhurya, mardana.
\end{abstract}

Kata Kunci: Agama Hindu, Etika, Sarasamuccaya.

\begin{abstract}
Ethics is part of the three teachings of the basic framework of Hinduism contained in the Sarasamuccaya book, the Sarasamuccaya book is a guideline for good behavior in human life, which contains religious and ethical teachings. The problem raised in this research is regarding the ethical aspects (teachings) in the Sarasamuccaya book, the purpose of this study is to examine the ethical aspects of the Sarasamuccaya book, while the benefits are expected to increase the insight and morals or ethics of Hindus as implied in the Sarasamuccaya book. The discussion of this research problem rests on three theories: religious theory, structuralfunctional theory, and symbol theory, ethical theory, and interpretation / hermeneutic theory. The research methods consist of: (1) data collection methods, (2) documentation methods, (3) data analysis methods, the
\end{abstract}


results of the assessment in this paper include: (1) Catur Purusa Artha, which consists of: dharma, artha, kama, and moksa; (2) Tri Kaya Parisudha, which consists of: kayika parisudha, wacika parisudha, and manacika parisudha; (3) respect for others and parents, and (4) the teachings of dasa yama, which consists of: Anrsangsya, ksama, satya, ahingsa, dama, arjawa, priti, prasada, madhurya, and mardana.

Keywords: Ethics, , Hinduism, Sarasamuccaya.

\section{PENDAHULUAN}

Umat Hindu pada zaman modern ini tidak jarang dijumpai yang mengabaikan ajaran luhur tentang ketuhanan dan lebih mementingkan kesenangan duniawi. Kemerosotan moral yang terjadi pada umat manusia tentunya akan dapat menimbulkan beragam masalah kehidupannya di dunia ini. Hal tersebut dikhawatirkan semakin luntur dan pudar bahkan hilangnya nilai-nilai luhur ajaran suci yang telah dijadikan pedoman berabad-abad dalam menjalani kehidupan beragama. Maka dari itu perlu terus dibina dan dikembangkan pemahaman umat memelalui pendidikan Agama Hindu, yang salah satunya sumbernya seperti yang termuat dalam kitab Sarasamuscaya.Denikian pula perlu adanya suatu pengkajian yang lebih mendalam mengenai upaya pembentukkan karakter umat Hindu melalui ajaran kitab Sarasamuccaya.

Agama Hindu memiliki kerangka dasar yang terdiri atas: (1) tattva (filsafat agama); (2) susila (etika); (3) acara (upacara dan upakara) (Titib, 2007: 26). Tattva adalah hakikat atau kebenaran suatu unsur, baik yang nyata ataupun yang tidak nyata termasuk hakikat Tuhan. Atau secara sederhana dapat diartikan sebagai hakikat kebenaran Tuhan beserta segala ciptaannya (Sanjaya, 2011: 39), Susila (Etika) berasal dari bahasa Sanskrta yang terdiri dari kata Su yang berarti baik, dan Sila yang berarti tingkah laku, jadi kata susila artinya tingkah laku yang baik sesuai dengan norma-norma yang hidup di masyarakat (Tim Penyusun, 2012: 147), Acara agama merupakan bentuk pelaksanaan ajaran Hindu yang didalamnya tercermin kegiatan praktis bagaimana, seharusnya menunjukkan rasa kasih dan bhakti kepada Tuhan ( Sang Hyang Widhi), kepada alam semesta, kepada sesama manusia, kepada leluhur/roh nenek moyang; dan kepada orang-orang suci.

Dalam agama Hindu, etika dinamakan sebagai susila yang diartikan sebagai kebiasaan atau tingkahlaku manusia yang baik, karena itu dalam Agama Hindu, etika dikatakan sebagai ilmu yang mempelajari tata nilai, tentang baik dan buruknya suatu perbuatan, sehingga muncul suatu situasi yang sinkron antar sesama manusia, antar manusia dengan lingkungan sekitarnya. Salah satu aspek yang dibahas dalam etika adalah tentang moral. Etika juga diartikan sebagai rasa cinta, dan kasih sayang. Dimana seorang yang menerima etika itu adalah karena ia mencintai dirinya sendiri dan menghargai orang lain, sifat tidak egoitis melaikan humanistis (Pudja, 1984;57-58). Etika sebagai bagian dari ajaran tri kerangka dasar Agama Hindu juga termuat dalam kitab Sarasamuccaya, Kitab Sarasamuccaya adalah salah satu dari pustaka 
suci Hindu yang mengandung nilai-nilai pendidikan yang berimplikasi terhadap karakter. Kitab Sarasamuccaya merupakan pedoman tingkah laku yang baik dalam kehidupan manusia, yaitu religi dan etika. Kalau ajaran Bhagavad Gita menyangkut filsafat maka kitab Sarasamuccaya berisikan ajaran etika (Sudharta, 2009: xiii).

Berdasarkan uraian di atas maka artikel ini diberi judul "Kajian Ajaran Etika dalam Kitab Sarasamuccaya". Adapun rumusan masalah penelitian ini yaitu, apa sajakah aspek (ajaran) etika dalam kitab Sarasamuccaya. Tujuan penelitian ini ingin mengetahui dan mengkaji ajaran etika dalam kitab Sarasamuccaya. Manfaatnya dapat meningkatkan wawasan ilmu pengetahuan keagamaan, moral atau etika umat Hindu yang terkandung dalam kitab Sarasamuccaya. Pemecahan masalah dalam penelitian ini bertumpu pada beberapa teori : teori religi, teori fungsional-struktural, teori simbol, teori etika dan teori interpretasi/hermeneutika. Teori religi dalam tulisan Koentjaraningrat (2005:60) disebutkan bahwa terdapat empat unsur religi yang dapat dipakai konsep dasar untuk menganalisis agama dalam kehidupan sosial masyarakat: (1) Emosi Keagamaan, yaitu suatu emosi yang menyebabkan manusia menjadi religius. (2) Sistem kepercayaan yang mengandung keyakinan serta imajinasi manusia tentang Tuhan, kebaradaan alam gaib, supranatural yaitu tentang hakikat dan wujud dewa-dewa yang berada di luar jangkauan manusia yang diajarkan kepada manusia melalui kitabkitab suci agama yang bersangkutan. (3) Sistem upacara religius adalah suatu cara yang bertujuan untuk mencari hubungan manusia dengan sang pencipta. (4) Komoditi agama (kelompok keagamaan), setiap agama pasti memiliki umat/pengikut yang melakukan praktik-praktik keagamaan.Teori fungsional - struktural, menurut Malinowski yang menekankan pada keteraturan (order) dan mengabaikan konflik serta perubahan-perubahan yang terjadi dalam masyarakat beragama. Menurut teori ini agama merupakan suatu sistem sosial yang terdiri dari bagian-bagian satu sama lain yang saling berhubungan, menyatu dalam keseimbangan. Perubahan yang terjadi pada satu bagian akan membawa perubahan pada bagianbagian lainnya. Dasar berpikir setiap struktur dalam sistem sosial fungsional, maka struktur dalam sistem sosial fungsional, maka struktur dalam sistem sosial itu akan hilang dengan sendirinya (Ariska, $2015: 24$ ). Teori simbol adalah sesuatu hal yang diterima dengan persetujuan umum sebagai yang mewakili atau yang menjadi ciri khas dari suatu yang dipenuhi dengan kualitas atau yang terdapat dalam kenyataan atau pikiran (Triguna, 2000 : 35). Teori etika adalah ilmu yang menjelaskan arti baik dan buruk, menerangkan apa yang seharusnya dilakukan oleh manusia, menyatakan tujuan yang harus dituju oleh manusia di dalam perbuatan mereka dan menunjukan jalan untuk melakukan apa yang seharusnya diperbuat (Ahmad Amin, 1983 : 3). Teori interpretasi/hermeneutika secara umum dapat diartikan sebagai suatu teori atau filsafat tentang interpretasi makna (Atho \& Arif Fahruddin, 2002 : 14). Hermeneutika adalah studi pemahaman, khusus pemahaman teks (Palmer, $2003: 8$ ). 


\section{METODE}

Penelitian ini dirancang dengan menggunakan studi literatur teknis, dengan beberapa metode antara lain: (1) metode pengumpulan data, yakni cara yang akan digunakan dalam memperoleh data-data yang berkaitan dengan objek penelitian. "teknik pengumpulan data ada beberapa jenis, hendaknya dipergunakan secara tepat sesuai dengan tujuan penelitian dan jenis data yang ingin digali serta keadaan subjek penelitian" (Amirin, 1990 : 94). Jenis penelitian ini adalah penelitian kualitatif yang datanya diperoleh dari studi pustaka, (2) metode dokumentasi, menurut Moleong (dalam Redana, 2006 : 167) menyatakan bahwa sumber data utama dalam penelitian kualitas adalah kata-kata dan tindakan, selebihnya adalah data tambahan seperti dokumen dan lain-lain. (3) metode analisis data, bahwa data dalam penelitian ini berwujud katakata, kalimat-kalimat, paragraf- paragraf yang dinyatakan dalam bentuk narasi yang bersifat deskriptif sebagai ciri khas dari penelitian kualitatif.

Dalam analisis data diperlukan pereduksian data, peneliti membuat suatu jenis catatan seperti membuat ringkasan ataupun kerangka berpikir. Adapun data yang direduksi atau dibuang adalah data yang tidak terkait dengan permasalahan penelitian kualitatif seperti ini yang sangat banyak sehingga kemungkinan ada data yang harus dibuang. Selanjutnya dilakukan transformasi data, yakni mengubah data menjadi bentuk lain agar efektif dan efisien tanpa mengubah dan menghilangkan substansinya. Data yang ditransformasikan dalam penelitian ini hanyalah data yang dipergunakan dalam analisis data. Setelah dilakukan transformasi data kemudian dilakukan penyajian Data. Menurut Miles dan Hubernam (1984 : 194) bahwa penyajian analisis data yang dimaksudkan untuk menemukan pola-pola yang bermakna serta memberikan kemungkinan adanya penarikan simpulan dan pengambilan tindakan penyajian analisis data. Setelah penyajian data dilakukan, maka langkah selanjutnya adalah penyimpulan sementara. Simpulan sementara akan diuji dengan simpulan-simpulan data yang tersaring dari hasil pengamatan berikutnya. Simpulan yang bersifat sementara ini akan ditarik suatu simpulan umum sebagai hasil penelitian akhir. Hal ini berarti sejak awal peneliti mengumpulkan data berusaha untuk mencari makna data yang dikumpulkan.

Nasution (1996 : 130) menegaskan, dari data yang diperoleh sejak awal, peneliti mencoba mengambil simpulan. Mula-mula simpulan itu masih bersifat tentative, kabur, diragukan, akan tetapi dengan bertambahnya data, maka simpulan itu akan lebih. Jadi simpulan senantiasa harus diverifikasi selama penelitian berlangsung untuk mendapat simpulan akhir dari hasil penelitian.

\section{PEMBAHASAN}

\subsection{Susunan dan isi kitab Sarasamuccaya}

Kitab Sarasamuccaya adalah salah satu dari pustaka suci Hindu yang mengandung nilai-nilai pendidikan yang berimplikasi terhadap karakter. Kitab ini adalah kitab etika untuk pemeluk-pemeluk Agama Hindu di Indonesia "The Sarasamuccaya is the Gita of the Balinese Hindus, 
Sarasamuccaya adalah Bhagavadgita-nya orang-orang Bali pemeluk Agama Hindu. Dalam kitab Sarasamuccaya terdapat ajaran tentang cara bertingkah laku untuk diri sendiri dan untuk hidup bersama dengan orang lain.

\subsubsection{Ajaran etika dalam kitab Sarasamuccaya}

Ajaran pokok kitab Sarasamuccaya ialah ajaran etika. Etika dapat diartikan sebagai pedoman atau hukum yang menuntun manusia dalam kehidupan bermasyarakat dan kehidupan sosial lainnya. Tanpa pedoman yang jelas untuk menuntun masyarakat dalam kehidupan sehari-hari, maka akan mudah sekali timbul kekacauan.

Dalam kitab Sarasamuccaya terdapat ajaran mengenai larangan, dan cara bertingkah laku yang baik dalam menjalankan kehidupan. Semua ajaran dalam kitab Sarasamuccaya berlandaskan ajaran Agama Hindu, ajaran untuk mencapai kelepasan (moksa).

Kitab Sarasamuccaya mengajarkan bahwa pembenahan diri sendiri mendapatkan tempat utama, disamping pembenahan diri dalam hubungan dengan orang lain. Hubungan antara hidup di dunia ini dengan hidup diakhirat mendapat perhatian yang besar dalam kitab Sarasamuccaya. Barang siapa yang hidup baik di dunia akan mendapat kebahagiaan diakhirat. Namun pembenahan hidup di dunia inilah yang terpenting, karena di dunia inilah tempat kita berbuat yang hasilnya akan kita nikmati di akhirat dan pada kelahiran yang akan datang.

Kelahiran ini merupakan tangga untuk naik ke sorga. Karena itu kelahiran ini harus diabadikan untuk meningkatkan diri dalam kebajikan supaya tidak jatuh ke neraka. Caranya ialah dengan melakukan dharma. Dalam tulisan ini diuraikan beberapa pokok ajaran kitab ini mengenai ajaran etika antara lain: catur purusa artha, trikaya parisudha, hormat kepada orang lain serta orang tua dan ajaran tentang dasa yama dan dasa niyama brata.

\section{(1) Catur Purusa Artha}

Walaupun kitab Sarasamuccaya tidak ada menyebut nama catur purusa artha, tetapi perincian dari catur purusa artha itu yaitu dharma, artha, kama, dan moksa beberapa kali disebut dan diuraikan maknanya dalam beberapa sloka. Hal ini misalnya dapat kita baca pada sloka 1 kitab ini, sebagai berikut:

Dharme carthe ca kame ca moksa ca bharatarsabha, yadihasti tadanyatra yannehasti na tat kvacit.

Anaku kamung janemejaya, salwirning warawarah, yawat makapadarthang caturwarga, sawataranya, sakopanyasanya, hana juga ya ngke, sangksepanya, ikang hana ngke, ya ika hana ing len sangkeriki, ikang tan hana ngke, tan hana ring len sang keriki. Terjemahan :

Oh engkau bantengnya keluarga bhatara, dalam lapangan dharma, artha, kama dan moksa, sebagaimana tertulis di sini terdapat juga di tempat lain, dan apa yang tidak tercantum disini tidak akan dijumpai di tempat lain. 
Catur purusa artha artinya empat tujuan hidup manusia. Memang hidup di dunia ini adalah untuk memenuhi kebutuhan kama yaitu keinginan, nafsu, yang mendorong orang untuk berbuat sesuatu, yang mendorong orang bergairah. Objek dari pada kama ini ialah artha yaitu benda-benda duniawi yang dapat memuaskan kama sehingga menjadikan orang nikmat merasakan hidup ini. Tetap dalam memenuhi tuntutan kama pada artha akan dapat membawa orang pada jurang kesengsaraan apabila tidak atas dasar dharma yaitu kebajikan, kebenaran peraturanperaturan yang mendukung orang untuk mendapatkan kebahagiaan. Maka itu dharmalah harus menjadi pengendali dalam memenuhi tuntutan kama atas artha. sloka 12 kitab Sarasamuccaya mengingatkan kita akan hal ini sebagai berikut :

Kamarthau lipsamanastu dharmamevaditasearet, na hi dharmadapetyarthah kamo vapi kadacana.

Yan paramathanya, yan artha kama sadhyan, dharma juga lakasakena rumuhu, niyata katemwaning artha kama menetan paramartha wi katemwa ning artha kama dening anasar sakeng dharma.

Terjemahan:

Pada hakekatnya jika artha dan kama dituntut, maka seharusnya dharma hendaknya dilakukan lebih dulu. Tak dapat disangsikan lagi, pasti akan diperoleh artha dan kama ini nanti. Tidak akan ada artinya, jika arta dan kama itu diperoleh menyimpang dari dharma.

Berdasarkan uraian diatas maka dharma mempunyai kedudukan yang paling penting dalam catur purusa artha, karena dharmalah yang mengantar orang mendapatkan kebahagiaan dalam menuruti kama menikmati artha di dunia ini karena itu dharma amat dipuji-puji dalam kitab ini dan orang terus menerus dihimbau untuk menjadikan dharma pedoman hidupnya, seperti dalam sloka 14 dan 16 kitab Sarasamuccaya:

Dharma eva plavo nanyah svargam samabhivachatam, sa ca naurpwanijastatam jaladheh paramicchatah. (S.S 14)

Ikang dharma ngaranya, henu ning mara ring swarga ika, kadi gati ning perahu, an henu ning banyaga nentas ing tasik

Terjemahan:

Yang disebut dharma adalah merupakan jalan untuk pergi ke sorga, sebagai halnya perahu yang merupakan alat bagi saudagar untuk mengarungi lautan.

Yathadityah samudyan vai tamah sarvam vyapohati evam kalyanamatistam sarvapapam vyapohati. (S.S 16)

Kadi krama sang hyang aditya, an wijil, humilangaken peteng ning rat, mangkana tikang wwang mulahakening dharma, an hilangakensalwiring papa

Terjemahan :

Seperti halnya matahari yang terbit melenyapkan gelapnya dunia, demikianlah orang yang melakukan dharma, memusnahkan segala macam dosa. 
Tentu saja orang-orang yang melanggar dharma, yang tidak mau menjadikan dharma jalan kehidupannya akan tidak mendapatkan kebahagiaan tetapi kesedihan lah yang akan dialami. Orang yang demikian itu adalah orang yang jatuh dalam adharma prawrtti. Hanya atas dasar dharma ini orang akan dapat mencapai kelepasan, lepas dari ikatan keduniawian ini, yang sesungguhnya merupakan tujuan akhir dari setiap orang. Lepas dari segala ikatan duniawi sehingga dapat menikmati kebahagiaan abadi disebut moksa. Demikianlah catur purusa artha itu.

Pada Kitab Bhagavad Gita juga menekankan ajaran moksa, terdapat tiga Sloka yang menekankan tentang moksa pada ajaran Bhagavad Gita, yaitu pada Bab XVIII Sloka 51,52, dan 53:

Bab XVIII Sloka 51:

Buddhya visuddhaya yukto

Dhrtyatmanam niyamya ca

Sabdadidin visayams tyaktva

Raga-dvesau vyudasya ca

Artinya:

Diperlengkapi dengan pengetahuan suci, teguh mengendalikan jiwa, menghindari suara dan objek panca indriya lain-lainnya serta menjauhi segala yang dicintai dan dibenci.

Bab XVIII Sloka 52:

Viviktasevi laghvasi

Yata vak kaya manasah

Dhyanayogaparo nityam

Vairagyam samupasritah

Artinya:

Berdiam ditempat suci, maka hanya sekedarnya perkataan, badan jasmani dan pikiran terawasi, selalu bermeditasi dan berkonsentrasi, serta bernaung dibawah kedamaian hati.

Bab XVIII Sloka 53:

Ahamkaram balam darpam

Kamam krodham parigraham

Vimucya nirmamah santo

Brahmabhuyaya kalpate

Artinya:

Membuang jauh-jauh egoisme, kekerasan, keangkuhan nafsu, amarah, dan harta kekayaan, suka bersosialisasi dan memiliki ketenangan pikiran ialah yang patut menjadi satu dengan Brahman.

Kerja apapun sebenarnya harus dilakukan, kerja harus dilaksanakan. Tetapi semua harus dilakukan dengan menghilangkan 
semua ikatan terhadap hasilnya. Ini bukan berarti bahwa seseorang harus melupakan tugasnya. Tugas harus dilakukan dan hanya hasil dan keterikatan yang harus dihilangkan. Orang yang melakukan yang bebas dari ikatan, yang tidak memiliki perasaan, yang tetap tegar dan bersemangat, yang tidak tergerak oleh keberhasilan atau kegagalan, yang pikirannya tidak terikat pada apapun, yang telah menarik dirinya dan dapat mengendalikan panca indera Nya, tidak memiliki keinginan, pantas untuk menyatu dengan Tuhan.

Panca indera kita sesungguhnya adalah ibarat kuda yang menarik kereta badan manusia ini. Kita akan terombang ambing apabila kita tidak cepat sadar serta mengendalikan panca indera itu dengan perasaan dan penuh kesadaran. Mengatasi hanya didasarkan pada akal (budhi) semata mata tidaklah ada manfaatnya melainkan harus diikuti dengan perasaan, ibarat kita memindahkan perasaan orang lain kedalam perasaan kita sendiri.

Usaha untuk dapat lepas dari sifat-sifat yang tidak baik ialah dengan jalan menguasai diri sendiri. Dalam hubungan ini Bhagawad Gita berulang kali menyebutkan agar orang dapat menguasai indrianya, karena indria yang menghubungkan manusia dengan dunia ini, dunia objek kesenangan. Dengan indrianya maka keinginan yang timbul dari dirinya itu dapat diarahkan kepada tujuan-tujuan yang baik yang membawa keselamatan kepada dirinya sendiri.

Bila seseorang selalu memikirkan benda-benda duniawi, ia akan terikat kepadanya. Dari ikatan muncul keinginan, dari keinginan muncul kemarahan, dari kemarahan muncul kebingungan, dari kebingungan hilang ingatan, hilang ingatan hancur pikiran, hancurnya pikiran membawa kemusnahan. Akan tetapi ia yang dapat mengendalikan pikirannya di tengah tengah benda benda duniawi dengan menguasai indrianya, bebas dari ikatan dan perasaan enggan, ia akan dapat mencapai ketenangan.

Dengan teguh mengendalikan diri, menjauhkan diri dari indria-indria dan objek-objek indria, menghilangkan perasaan suka dan tidak suka, tinggal menyendiri, mengendalikan perkataan, tubuh dan pikiran, terikat dalam meditasi dan konsentrasi, bebas dari nafsu, menghilangkan kecurangan, kekerasan, harga diri, keinginan kemarahan, dan kepemilikan, dan menyempurnakan pikiran, ia pantas untuk menyatu dengan Tuhan.

Setelah menyatu dengan Tuhan dan menyempurnakan jiwa tanpa duka atau keinginan. la menganggap bahwa semua makhluk hidup itu sama dan ia mengabdikan dirinya pada Tuhan. Mungkin ia selalu terikat dengan semua jenis pekerjaan, dan setelah ia berlindung pada Tuhan, ia mencapai keabadian dan tidak akan mengalami kehancuran atas berkahNya.

Demikianlah ajaran moksa yang terdapat dalam kitab Sarasamuccaya dan kitab Bhagavadgita.

\section{(2) Trikaya Parisudha}

Setiap hal yang kita lakukan berlangsung melalui trikaya, tiga anggota badan yaitu : kaya, wak dan manah. Kaya ialah anggota badan, seperti tangan, kaki, punggung, mulut dan sebagainya, sedangkan wak 
ialah kata-kata dan manah adalah pikiran Dengan tiga alat inilah manusia bisa berbuat sesuatu, baik terhadap dirinya sendiri maupun terhadap orang lain, dan lingkungannya. Karena itu ketiga anggota badan ini mendapat perhatian besar dalam ajaran etika Hindu seperti dalam kitab Sarasamuccaya yaitu Agastyaparwa. Sebutan trikaya itu dalam kitab sarasamuccaya kita dapati dalam sloka 157 sebagai berikut:

Adrohah sarvabhutesu,

Kayena manasa gira,

Anugrahasca danam ca,

Silametadvidurbudhah. (S.S 157)

Ikang kapatyaning sarwabhawa, haywa jugenulaheken, makasadhanang trikaya, nang kaya, wak manah, kuneng prihen ya ring trikaya anugraha lawan dana juga, apan ya ika sila ngaranya, ling sang pandita

Terjemahan:

Yang membuat matinya segala makhluk hidup, sekali-kali jangan hendaknya dilakukan dengan menggunakan trikaya, yaitu perbuatan dan pikiran. Adapun yang harus diiktiarkan dengan trikaya, hanyalah pemberian dan sedekah saja, sebab itulah disebut sila, kata orang arif.

Tiga anggota badan itu dapat digunakan untuk tujuan-tujuan yang buruk dan dapat pula digunakan untuk tujuan-tujuan yang baik. Bila orang dapat menggunakan untuk tujuan-tujuan yang baik, maka trikaya itu akan disebut trikaya parisudha artinya tiga anggota badan yang telah disucikan meliputi: kayika parisudha, waciaka parisudha, dan manacika parisudha. Inilah yang diperintahkan oleh ajaran agama untuk dilaksanakan dalam hidup ini, supaya mendapatkan kerahayuan untuk diri sendiri maupun kerahayuan untuk orang lain. Berikut ini akan disajikan uraian singkat masing-masing bagian Tri Kaya parisudha.

\section{a. Kayika Parisudha}

Kayika parisuda dapat kita rumuskan sebagai segala perilaku yang berhubungan dengan badan yang telah disucikan. Ini berarti segala yang disebut cemar serta terlarang tidak dilakukan oleh anggota badan ini. Semua orang pun maklum bahwa selama hayat di kandung badan selama itu kita harus berbuat karena hidup ini adalah untuk berbuat. Kehadiran kita di dunia ini akan sia-sia belaka, bila tidak digunakan untuk berbuat sesuatu Dengan berbuat itu berarti kita telah membuat suatu karma yang akan menentukan hidup kita pada masa-masa yang akan datang. Karena kita mengharapan hidup yang lebih baik pada hari yang akan datang, maka sekaranglah waktunya kita menanam karma yang baik dengan menghindar dari perbuatan-perbuatan yang buruk. Dalam hubungan ini kitab Sarasamuccaya, sloka 76 menyebut demikian:

Pranatipatam stainyam ca

Paradaranathapi va,

Trini papani kayena 
Sarvatah parivarjavet. (S.S 76)

Nihan yan tan ulahakena, syamati mati, mangahal ahal, siparadar, nahan tang telu tan ulahakena ring asing ring parihasa, ring apatkala, ring pangipyan tuwi singgahana juga

Terjemahan :

Inilah yang tidak patut dilakukan : membunuh, mencuri, dan berbuat zina.

Ketiganya itu janganlah hendaknya dilakukan teradap siapapun baik secara berbohong, dalam keadaan dirundung malang, dalam hayalan sekali pun hendaknya dihindari semua itu.

Tentu saja tidak hanya yang disebut diatas itu saja yang harus tidak dikerjakan orang. Segala sesuatu yang dikerjakan dengan badan seperti mengambil, memukul, menendang, mendesak, mencium, menggigit dan sebagainya yang bertentangan dengan perbuatan yang baik dan benar harus dijauhi.

b. Wacika Parisudha

Berkata yang benar dan baik disebut orang wacika parisudha. Hampir setiap hari orang berkata-kata untuk menyampaikan isi hatinya kepada orang lain. Pengetahuan kita sebagaian besar kita peroleh melalui kata-kata, baik secara lisan maupun secara tertulis. Dengan demikian kata-kata itu memiliki kedudukan dan peranan amat penting dalam kehidupan kita. la dapat mendatangkan kebahagiaan untuk diri sendlri atau menarik simpati orang lain. la dapat merupakan tirtha amrta yang sejuk nyaman, yang menghibur dan menghidupkan semangat orang. Tetapi ia dapat juga menjadi racun yang menghancurkan, merusak jiwa dan raga manusia.

Seringkali orang-orang tidak sadar akan dirinya sehingga terhamburlah dari mulutnya kata-kata yang tidak patut diucapkan yang membawa kerugian kepada dirinya sendiri dan kepada orang lain. Oleh karena itu kesadaran akan diri dan ketenangan hati adalah faktor yang peling benar pada waktu kita berbicara. Dalam kitab Sarasamuccaya sloka 75 menyebutkan empat hal yang tidak boleh dilakukan dengan kata-kata.

Empat hal ini seperti berikut:

Asatplarapam parusyam

Paisunyamanrtam tahta, catvari vaca rajendra, na jalpennanucintayet. (S.S 75)

Nyang tanpa prawrttyaning wak, pat kwehnya, pratekanya ujar ahala, ujar apregas ujar pisuna, ujar mithya, nahan tangpat sinnanggahananing wak, tan ujarakena, tan angen-angenan kojaranya

Terjemahan : 
Inilah yang tidak patut timbul dari kata-kata, yaitu : perkataan jahat, perkataan kasar, perkataan memfitnah, perkataan bohong.

Didalam Manawa Dharmasastra juga disebutkan mengenai wacika parisudha salah satunya pada sloka 161 yang isinya sebagai berikut:

Narumtudah syad arto'pi na

Paradroha karmadhih,

Yayasyodvijate vaca

Nalokyam tamudarayet.

Artinya :

Meski marah atau sedih janganlah memakai kata kasar

Janganlah menyakiti orang lain dalam pikiran

Jangan berkata yang menyebabkan orang lain takut

Hal itu dapat menghalanginya mencapai sorga

\section{c. Manacika parisudha}

Pikiran mendapat perhatian besar dalam ajaran yoga, karena pikiranlah sumber segala apa yang kita lakukan, sumber segala yang dikatakan orang. Bila pikiran menyuruh anggota badan diam, maka anggota badan pun diam, bila pikiran menyuruh mulut tak berkata, maka mulut pun diam. Pikiranlah yang menentukan segala perbuatan orang. Dengan demikian anggota badan tidak akan berbuat apapun, tidak mengetahui sesuatu bila pikiran tiada menyertainya, karena sesungguhnya pikiranlah yang mengetahui dan merasakan sesuatu. Hal ini dinyatakan dalam kitab Sarasamusccaya sloka 82 berikut:

Sarvam pasyati caksusman

Manoyuktena caksusa,

Manasi vyakule jate

Pasyannapi na pasyati.

Lawan tattwaniking manah, nyan mata wuwusanta, nang mular ring sarwa wastu, manah juga sahaya ning mata nikang wulat, kunang yan wayakula manahnya, tan ilu sumahayang mata, mulata towi nikang wastu, tan katon juga ya de nika, apan manah ikang wawarengo ngaranya hinganyan pradhanang manah kalinganika.

Terjemahan :

Dan lagi sifatnya pikiran itu bahwa mata dikatakan dapat melihat berbagai barang, tiada lain hanya pikiran yang menyertai mata itu memandang. Maka jika pikiran binggung atau kacau, tidak turut menyertai mata sungguh pun memandang kepada suatu barang tidak terlihat barang itu olehnya, sebab itu sesungguhnya pikiranlah yang memegang peranan utama.

Oleh karena pikiran itu sumber segala perbuatan, maka ia harus dihindari dari kehendak yang buruk dan kotor dengan mengendalikannya. 
Dengan mengendalikan pikiran itu serta mengarahkan kepada hal-hal yang baik dan luhur maka berarti membina kepribadian sendiri secara keseluruhan yang akhirnya akan membawa diri kepada ketentraman dan kesucian.

Dalam kitab-kitab agama Hindu banyak terdapat ajaran Tri Kaya Parisudha seperti halnya dalam kitab Bhagavad Gita. Dalam Bhagavad Gita, yaitu pada Bab XVII Sloka 14, 15, dan 16.

Bab XVII Sloka 14:

Deva-dvija-guru-prajna

Pujanam saucam arjuvam

Brahmacaryam ahimsa ca

Sariram tapa ucyate

Artinya:

Melakukan pemujaan sepantasnya kepada para Dewa, para Brahmana, guru spiritual (bapak, ibu), menjaga kebersihan, kesederhanaan, berpantang hubungan seksual dan tidak melakukan kekerasan, semua ini dikatakan sebagai pertapaan badan.

Bab XVII Sloka 15:

Anudvega-karam vakyam

Satyam priya-hitam ca yat

Svadhyayabhyasanam caiva

Van-mayam tapa ucyate

Artinya:

Kata-kata yang tidak menyebabkan perasaan orang lain terganggu, jujur, menyenangkan dan mengandung kebaikan serta kata-kata yang dipergunakan untuk belajar serta mempraktekkan pembacaan kitab suci Veda, semua itu dikatakan sebagai pertapaan kata.

Bab XVII Sloka 16:

Manah-prasadah saumyatvam

Maunam atma-vinigrahah

Bhava-samsuddhirity etat

Tapo manasam ucyate

Artinya:

Pikiran yang puas dalam segala keadaan, kesadaran yang menyejukkan, suka merenung, suka mengendalikan pikiran, berusaha sepenuhnya menyucikan pikiran, semua itu dikatakan sebagai pertapaan pikiran.

Pada ketiga Sloka tersebut tentang ajaran Tri Kaya Parisudha. Tingkah laku, pikiran dan perkataan yang baik dapat dicapai dengan Karma Patha yaitu pengendalian diri. Dengan akal yang dikaruniai Tuhan, kita harus mampu mengedalikan tingkah laku dan perkataan melalui analisa logis tentang yang baik dan yang buruk. Justru dalam kemampuan membedakan antara yang baik, yang benar dan buruk, yang jahat, itulah letak kelebihan manusia dari makhluk lainnya. 
Pengendalian diri ajaran Tri Kaya Parisudha yaitu pada manacika (pikiran yang baik), manusia diajarkan untuk tidak menginginkan sesuatu yang tidak baik atau dilarang oleh ajaran agama, tidak berpikir buruk terhadap orang lain, tidak mengingkari hukum Karma Phala. Pengendalian diri pada wacika (berkata yang baik), manusia diajarkan untuk tidak mencaki maki orang lain, tidak berkata-kata kasar pada orang lain, tidak memfitnah, dan tidak ingkar terhadap janji. Kemudian pengendalian diri pada kayika (berbuat yang baik), manusia diajarkan untuk tidak menyiksa makhluk lain, tidak membunuh, tidak curang dan tidak berzinah atau melakukan hubungan seksual diluar nikah.

\section{(3) Hidup saling bantu membantu dan hormat menghormati}

Manusia adalah makhluk sosial yang tidak dapat hidup sendirian dan selalu hidup bersama orang lain, karena satu dengan yang lain saling bergantungan. Supaya hubungan hubungan manusia menjadi harmonis maka ia harus rela berkorban, yaitu bersedia menerima dan memberi dengan sesama hidup. Setiap orang memiliki kelebihan dan kekurangan dari yang lain, baik berupa harta benda maupun kemampuan. Karena itu bagi yang lebih harus bersedia menerima atau mendermakan kelebihannya kepada yang kurang dan yang kurang harus bersedia menerima dari yang lebih. Demikian kitab Sarasamuccaya mengajarkan kita supaya bersedia berdana karena sesunggunya apa yang kita miliki adalah juga untuk membantu orang lain. Hal ini terdapat dalam kitab Sarasamuccaya sloka 178 sebagai berikut:

Dhanena kin janna dadati nasnute balena kin yena ripun na badhate, srutena kin yena, dharma macaret kimatnayo na jitendriyo vasi.

Ndya kari doning dhana, yang tan danakkena, tan tan bhutin, mangkanang kasaktin, tan padan ika yan tan sadhana ning mangalahanang musuh, mangkanang aji, tan padon ika yan tan suluha ri ng dharmasadhana, mangkanang buddhi kaprajinana tan padon ika yan tan pangalahakenendrya, tan pangawasakenang rajah tamah.

Terjemahan :

Apa gerangan gunanya kekayaan bila tidak untuk disedekahkan dan untuk dinikmati. Demikian pula kesaktian, tidak ada gunanya jika bukan alat untuk mengalahkan musuh. Demikian pula ajaran suci tidak ada gunanya bila tidak untuk suluh dalam pelaksanaan dharma. Demikian pula budi yang arif bijaksana tidak ada gunanya bila tidak untuk menaklukkan hawa nafsu, agar tidak dikuasai rajah tamah.

Jadi uraian diatas menyarankan agar segala kemampuan dan kelebihan itu supaya disumbangkan dan dipakai untuk menimgkatkan kesejahteraan hidup ini. Namun tidak semua orang patut diberi dana, sebab kalau kita berdana punia kepada orang dustacara, orang jahat, maka sumbangan itu akan sia-sia, karena akan dipakainya merusak bahkan mungkin untuk mencelakakan yang berdana punia.

Jadi dengan demikian hidup ini harus bantu membantu serta saling menghormati karena setiap orang mempunyai kelemahan-kelemahan sendiri yang harus dibantu oleh orang lain. 


\section{(4) Dasa Yama dan Dasa Niyama Brata}

Bila dalam astangga yoga terdapat ajaran panca yama niyama, maka dalam dalam kitab Sarasamuccaya terdapatlah ajaran dasa yama niyama brata. Ajaran ini adalah ajaran etika yang amat luhur.

Dalam ajaran yama brata ini, sifat-sifat mulia itu menunjukan sifatsifat yang mengarah pada obyek di luar diri, sedangkan pada niyama brata hampir menunjukan sifat-sifat yang mengarah ke dalam diri kita. Tampaklah di sini bahwa kita harus baik kepada sesama hidup, namun untuk dapat berbuat demikian maka diri sediri haruslah baik terlebih dahulu. Tidaklah mungkin orang berbuat baik kepada orang lain bila dirinya sendiri tidak baik. Tidak mungkin ada air jernih mengalir dari sumber yang keruh. Karena itu ajaran etika dalam ajaran agama Hindu selalu mengajarkan pembenahan pribadi lahir bathin, wahya adhyatmika. Adapun dasa yama brata perinciannya seperti di bawah ini :

Anrsamsyam ksama satyamahimsa dama arjavam, pritih prasado madhuryam mardavam ca yama dasa. (S.S 259)

Nyang brata ikang inaranam yama, pratyekanya nihan, sapuluh, kwehnya, anrsangsya, ksama satya, ahingsa, dama arjawa, priti, prasada, madhurya, mardawa, nahan pratekanya sapuluh, anrsangsya, si harimbawa, tan swartha kewala, ksama si kelan panastis, satya, si tan mrsawada, ahingsa, manuke sarwa, bhawa, dama, si upasama wruh mituturi manahnya, arjawa, si duga-duga bener, priti, si gong karuna, prasada, heningning manah, madhurya, manisning wulat lawan wuwus, mardawa, pos ning manah.

Terjemahan:

Inilah brata yang disebut yama, perinciannya demikian : anrsangsya artinya tidak mementingkan diri sendiri, ksama artinya tahan akan panas dan dingin, satya artinya tidak berdusta, ahingsa artinya membahagiakan semua makhluk, dama artinya sabar dapat menasehati diri sendiri, arjawa artinya tulus hati dan berterus terang, priti artinya sangat welas asih, prasada artinya jernih hatinya, madhurya artinya manis pandangan dan manis perkataan, mardana artinya lembut hati.

Demikian perincian dasa yama brata. Sedangkan dasa niyama brata, adapun perincianya sebagai berikut:

Danamijya tapo dhyanam svadhyyayopasthannigrahah vratopavasamaunam ca ananam ca nyama dasa. (S.S 260)

Nyang brata sapuluh kwehnya, ikang niyama ngaranya, pratyekanya, dana, ijya, tapa, dhyana, swadhyaya, upasthanigraha, brata upawasa, mauna snana, nahan ta awakning niyama, dana weweh, annadanadi; ijya, dewapuja, pitrpujadi, tapa kayasangcosana, kasatan ikang carira, bhucarya, jalatyagadi; dhyana, ikang ciwasmarana, swadhyaya, wedabhyasa, upasthanigraha, kahrtaning upastha, brata annawarjadi, mauna, wacangyama, kahrtaning ujar, haywakeceng kuneng, snana, trisangdhyasewana, madyusa ring kalaning sandhya 
Terjemahan:

Inilah brata sepuluh banyaknya yang disebut niyama dan perincianya: dana yaitu pemberian makanan dan minuman, tapa yaitu pengekangan nafsu jasmaniah, dhyana yaitu terfokus merenungkan Bhatara Siva, ljya yaitu pemujaan kepada dewa dan leluhur, swadhyaya yaitu mempelajari Veda, upasthanigraha yaitu pengekangan nafsu kelamin, brata yaitu pengekangan nafsu terhadap makan dan minum, mona yaitu menahan untuk tidak mengucapkan kata-kata sama sekali, snana yaitu tri sandhya dan membersihkan diri pada waktu pagi,siang dan sore hari.

\section{SIMPULAN DAN SARAN}

Berdasarkan analisis di atas disimpulkan bahwa Kitab Sarasamuccaya mengandung ajaran pokok etika Hindu, yang meliputi: catur purusa artha, trikaya, hormat kepada orang lain dan orang tua dan ajaran tentang dasa yama serta dasa niyama.

Berbagai ajaran bertingkah laku yang baik dan dilarang yang terdapat dalam kitab suci Sarasamuccaya itu sangat penting untuk dipahami guna meningkatkan Sradha bhakti umat Hindu ke hadapan Ida Sang Hyang Widhi Wasa.

Mengingat keterbatasan kemampuan, waktu, dan materi yang ada pada peneliti maka disarankan kepada para peneliti lain yang berminat terhadap studi ini untuk dapat mengembangkan dalam jangkauan yang lebih luas aspek-aspek lain yang belum terjangkau di sini agar hasil penelitian selanjutnya menjadi lebih sempurna. 


\section{DAFTAR PUSTAKA}

Ahmad Amin. 1983. Etika (IImu akhlak). Terjemahan KH. Farid Ma'ruf. Amirin. 1990. Menyusun Rencana Penelitian. Jakarta: Cv.Rajawali.

Ariska Dewi. 2014. Kajian Pendidikan Hindu Dalam Pasraman Ratu Bagus Manik Merta Di Banjar Delod Bale Agung Kecamata Mengwi.

Atho, Nafisul, dan Arif Fachruddin (editors). 2002. Hermeneutika Transendental. Yogyakarta : Ircisod (Online) Tersedia https://www.pengertianmenurutparaahli.net/pengertianinterpretasi (diakses pada 30 Juni 2020, pukul 11.00 Wita).

Atmaja dkk., I Made Nada. 2010. Etika Hindu. Surabaya : Paramita. http://ikp31 suardana.blogspot.com/2016/11/makalahtata-susila-ajaran-etika-dalam.html (diakses pada 2 Juli 2020, pukul 10.45 Wita) http://sitya10.blogspot.com/2013/09/makalah-bhagavad-gita-4ajaran.html (diakses pada 2 Juli 2020, pukul 09.30 Wita) https://agungsuparsa78.blogspot.com/2016/12/nilai-etika-dalamkitab-sarasamuscaya.html (diakses pada 30 Juni 2020, pukul 12.00 Wita)

Jakarta : Bulan Bintang (Online). Tersedia dalam https://www.seputarpengetahuan.co.id/2015/10/15-pengertian-etikamenurut-para-ahli-terlengkap (diakses pada 30 Juni 2020, pukul 10.00 Wita).

Kajeng dkk., I Nyoman. 1994. Sarasamuccaya. Jakarata : Hanuman Sakti.

Koentjaraningrat. 2005. Pengantar Antropologi II. Jakarta : Rineka Cipta. Miles, Mattew. B, dan A. Michael Hubermen. 1992. Analisis Data Kualitatif. Terjemahan oleh Tjeptjep Rohendi Rohidi. Jakarta: Universitas Indonesia.

Nasution. 1996. Metode Research (Penelitian IImiah). Jakarta : Bumi Aksara.

Pendit, Nyoman 1995. Bhagavad Gita. Jakarta : Hanuman Sakti (Online). Tersedia

Pudja, Gede. 1984. Pengantar Agama Sraddha. Denpasar : Masayasari.

Pudja, Gede. 2006. Sarasamuccaya. Surabaya : Paramita.

Sanjaya, Putu. 2011. Filsafat Pendidikan Agama Hindu. Surabaya: Paramita

Sudartha, Tjok Rai. 2007. Ajaran Moral Dalam Bhagavad

Gita. Surabaya : Paramita (Online). Tersedia

Sudartha, Tjok Rai. 2009. Sārasamuccaya (Smerti Nusantara). Surabaya: Paramita.

Sura, I Gede. 1985. Pengendalian Diri dan Etika. Denpasar : Pemerintah Propinsi Bali.

Sura, I Gede. 2006. Siwa Tattwa. Denpasar: Pemerintah Propinsi Bali.

Tim Penyusun. 2009. Kamus Besar Bahasa Indonesia Edisi baru. Jakarta: PT Media Pustaka Phoenix.

Tim Penyusun. 2012. Pembelajaran Nilai Karakter. Jakarta : PT. Raja Grafindo Persada. 
Titib, I Made. 2003. Menumbuhkembangkan Pendidikan Budhi Pekerti Pada Anak Dalam Perspektif Agama Hindu. Jakarta: Ganeca Exact.

Triguna. 2000. Teori Simbol. Denpasar: Universitas Hindu Indonesia. 